\title{
Incidence and outcomes of chronic total occlusion percutaneous coronary intervention in the Netherlands: data from a nationwide registry
}

\author{
A. van Veelen · B. E. P. M. Claessen · S. Houterman · L. P. C. Hoebers · J. Elias · J. P. S. Henriques · P. Knaapen for \\ the PCI Registration Committee of the Netherlands Heart Registration
}

Accepted: 5 November 2020 / Published online: 2 December 2020

(C) The Author(s) 2020

\begin{abstract}
Background Patients with chronic total coronary occlusions (CTO) are at increased risk for poor clinical outcomes. We aimed to determine the incidence of CTO percutaneous coronary intervention (PCI) and to identify CTO patients at risk for cardiac events in the nationwide Netherlands Heart Registration (NHR).

Methods We included all PCI procedures with $\geq 1$ CTO registered in the NHR from January 2015 to December 2018, excluding acute interventions. We used multivariable logistic regression of baseline characteristics to calculate the risk for events as odds ratios (OR) with 95\% confidence intervals (CI).

Results Of the PCIs performed during the study period, $6.3 \%(8,343 / 133,042)$ were for CTOs, with the percentage increasing significantly over time from
\end{abstract}

The members of the PCI Registration Committee of the NHR are listed in the backmatter of this article.

Electronic supplementary material The online version of this article (https://doi.org/10.1007/s12471-020-01521-y) contains supplementary material, which is available to authorized users.

A. van Veelen · L. P. C. Hoebers · J. Elias · J. P. S. Henriques Department of Cardiology, Heart Centre, Amsterdam Cardiovascular Sciences, Amsterdam UMC, University of Amsterdam, Amsterdam, The Netherlands

B. E. P. M. Claessen

Department of Cardiology, Northwest Clinics, Alkmaar, The Netherlands

S. Houterman

Netherlands Heart Registration, Utrecht, The Netherlands

P. Knaapen $(\bowtie)$

Department of Cardiology, Heart Centre, Amsterdam

Cardiovascular Sciences, Amsterdam UMC, VU University,

Amsterdam, The Netherlands

p.knaapen@amsterdamumc.nl
$5.9 \%$ in 2015 to $6.6 \%$ in $2018(p<0.001)$. Coronary artery bypass grafting $<24 \mathrm{~h}$ was carried out in $0.3 \%$, and the only significant predictor was diabetes mellitus (OR 2.97, 95\% CI 1.04-8.49, $p=0.042$ ). Myocardial infarction $(\mathrm{MI})<30$ days occurred in $0.5 \%$, and renal insufficiency (i.e. estimated glomerular filtration rate $<30 \mathrm{ml} / \mathrm{min}$ per $1.73 \mathrm{~m}^{2}$ ) was identified as an independent predictor (OR 4.70, 95\% CI 1.07-20.61, $p=0.040$ ). Among patients undergoing CTO-PCI, 1-year mortality was $3.7 \%$, and independent predictors included renal insufficiency (OR 5.59, 95\% CI 3.25-9.59, $p<0.001)$, left ventricular ejection fraction $<30 \%$ (OR 3.43, 95\% CI 2.00-5.90, $p<0.001$ ), previous MI (OR 1.62, 95\% CI 1.14-2.31, $p=0.007$ ) and age (OR 1.06 per year increment, 95\% CI 1.04-1.07, $p<0.001$ ). Target-vessel revascularisation $<1$ year occurred in $11.3 \%$.

Conclusion CTO-PCI is still infrequently performed in the Netherlands. The most important predictor of mortality after CTO-PCI was renal insufficiency. Identification of patients at risk may help improve the prognosis of CTO patients in the future.

Keywords Chronic total occlusion - Percutaneous coronary intervention · Mortality · Renal insufficiency

\section{Introduction}

A chronic total coronary occlusion (CTO) is the ultimate expression of coronary artery disease and defined as $100 \%$ obstruction of the coronary lumen with complete cessation of antegrade blood flow [1]. CTOs mostly result from progressive atherosclerotic disease, but can also emanate from previous asymptomatic or untreated myocardial infarction (MI) [2]. Accordingly, the incidence of CTOs was rather high in the thrombolysis era, with registries from the 1990s reporting incidences of $\sim 50 \%$ in patients undergoing diagnos- 
tic coronary angiography [3]. This incidence has decreased over the past two decades, and a CTO is now reported to be present in approximately $20 \%$ of patients undergoing coronary angiography and in approximately $15 \%$ of patients with acute ST-segment elevation myocardial infarction (STEMI) [4-7]. The presence of a CTO is associated with ischaemic symptoms and poor clinical outcomes, such as impaired left ventricular ejection fraction (LVEF), and increased risk for cardiogenic shock and mortality $[6,8]$.

Percutaneous coronary intervention (PCI) for a CTO is considered the final frontier for the interventional cardiologist and is performed in only $10 \%$ of all CTOs [5]. In the Netherlands, the total number of PCI procedures has grown considerably since the early 1990s, while the proportion of CTO procedures has only slightly increased [9]. However, due to novel techniques, improved devices and dedicated highrisk PCI programs and operators, the technical success rates of CTO-PCI are increasing, which allows revascularisation of more complex CTOs [10]. Therefore, the aforementioned numbers may be outdated. Here, we provide the contemporary results of CTOPCI from a Dutch nationwide registry. We aimed to identify factors that predict the risk of poor outcomes after CTO-PCI to improve patient selection for CTO revascularisation.

\section{Methods}

\section{Study design}

The Netherlands Heart Registration (NHR) is a nationwide registry initiated in 2017, merging three national registries [11]. The NHR registers outcomes of various cardiac interventions, including PCI, from the 30 hospitals in the Netherlands that perform PCIs. Data collection and registration are performed by the participating centres in a secure online environment. In the current study, we included all interventions registered from January 2015 to December 2018 that included a PCI with $\geq 1$ CTO in one of the treated vessels. All interventions with out-of-hospital cardiac arrest, cardiogenic shock or STEMI at admission, as well as all follow-up procedures, were excluded from the analysis. The research protocol of the current study was approved by the NHR Steering Committee. A waiver for informed consent for participation in the NHR was previously obtained from the Ethics Committee.

In this study, we aimed (1) to describe the current rate of CTO-PCI in the Netherlands and (2) to identify risk factors that are predictive of the clinical outcomes 1-year mortality, target-vessel revascularisation (TVR) $<1$ year, urgent coronary artery bypass grafting (CABG) $<24 \mathrm{~h}$ and $\mathrm{MI}<30$ days.

\section{Definitions}

The definitions are in accordance with the NHR Handbook, available via www.nederlandsehartregistratie.nl. A CTO was defined as an atherosclerotic occlusion in one of the treated vessels, older than 3 months and with a thrombolysis in myocardial infarction (TIMI) flow grade of 0 or 1 [1]. Multivessel disease was defined as the presence of a stenosis with $>70 \%$ luminal narrowing in $>2$ native major coronary arteries or first-order side branches. Non-ST-segment elevation myocardial infarction (NSTEMI), including unstable angina pectoris, was defined as acute chest pain, in the absence of ST-segment elevation. LVEF was measured at a maximum of 6 months prior to the intervention. When only a descriptive LVEF was provided, this was converted to percentages as follows: good/ normal $=55 \%$; moderate $=40 \%$; poor $=25 \%$; severely depressed $=20 \%$. Renal insufficiency was defined as an estimated glomerular filtration rate (eGFR) of $<30 \mathrm{ml} / \mathrm{min}$ per $1.73 \mathrm{~m}^{2}$. TVR was defined as repeat PCI in the index coronary artery during follow-up. The outcome measures were CABG within $24 \mathrm{~h}$ after PCI, MI within 30 days after PCI [including NSTEMI and STEMI, excluding periprocedural MI (i.e. type $4 \mathrm{MI}$, occurring within $48 \mathrm{~h}$ after PCI)], TVR within 1 year after PCI and 1-year mortality after PCI.

\section{Statistical analysis}

Normality of numerical data was determined using visual assessment of histograms. Normally distributed numerical data were described as mean \pm standard deviation (SD) and compared using Student's $t$-test. Non-normally distributed numerical data were described as median with interquartile range (IQR) and compared using the Mann-Whitney U test. Categorical data were described as frequencies with percentages and compared using Fisher's exact test or

\section{What's new?}

- The proportion of percutaneous coronary interventions (PCIs) performed for chronic total occlusions (CTOs) is currently still only $6.3 \%$, but the number of procedures has increased in recent years.

- CTO patients are younger, more often male and have more extensive cardiovascular comorbidities than non-CTO patients.

- The presence of renal insufficiency in CTO patients is the most important predictor of mortality and 30-day myocardial infarction, and should be taken into account when referring patients for CTO revascularisation.

- It is proposed that more CTO-PCI-specific parameters should be reported in national PCI databases. 


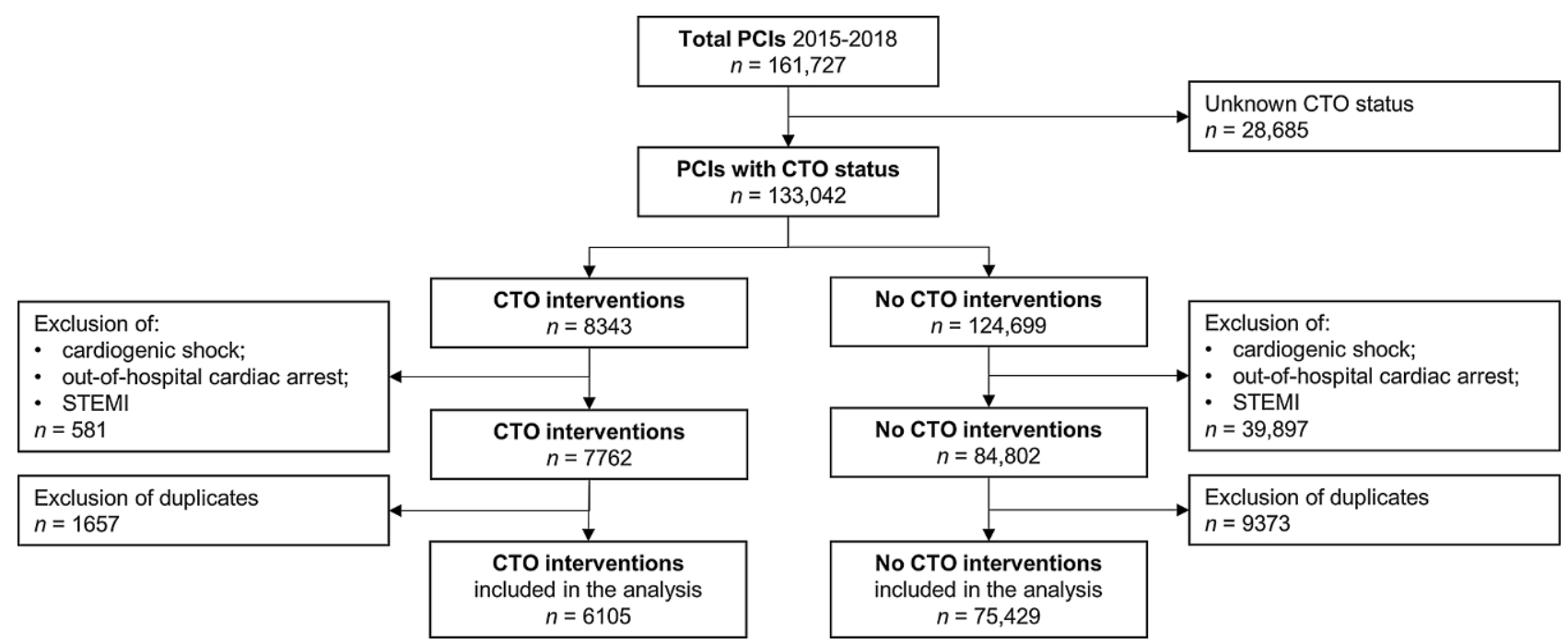

Fig. 1 Flowchart of percutaneous coronary intervention $(P C /)$ patients registered in the Netherlands Heart Registration between 2015 and 2018. CTO chronic total occlusion, STEMI ST-segment elevation myocardial infarction

the chi-square test. The rate of CTO-PCI was calculated as the total number of CTO-PCIs (including both primary and follow-up procedures, as well as cardiogenic shock, out-of-hospital cardiac arrest and STEMI procedures) relative to the total number of PCIs in the study period, and the change over the study period was tested with the chi-square test. Logistic regression was performed to test the predictive value of baseline characteristics for the outcomes of interest. For variables with $>20 \%$ of missing data (i.e. LVEF and previous PCI), a dummy category for the missing values was included in the regression model (not shown in the tables). All significant $(p<0.05)$ or relevant predictors from the univariable model were inserted in an enter model for multivariable logistic regression. The impact of the assessed risk factors on outcomes was described as odds ratio (OR) with corresponding 95\% confidence interval (CI). For the analysis of 1-year mortality and 1-year TVR, all cases with an intervention date in 2018 were excluded, since 1-year follow-up had not been completed at the time of this study. Survival curves were constructed using the Kaplan-Meier method and compared using the log-rank test. All statistical analyses were performed using SPSS 26 (IBM Corp. Released 2019. IBM SPSS Statistics for Windows, Version 25.0. Armonk, NY, USA).

\section{Results}

\section{Baseline characteristics}

A total of 161,727 PCI procedures were registered in the NHR, performed between 1 January 2015 and

Fig. 2 Temporal trend regarding the percentage of percutaneous coronary interventions (PC/s) performed for chronic total occlusion (CTO)

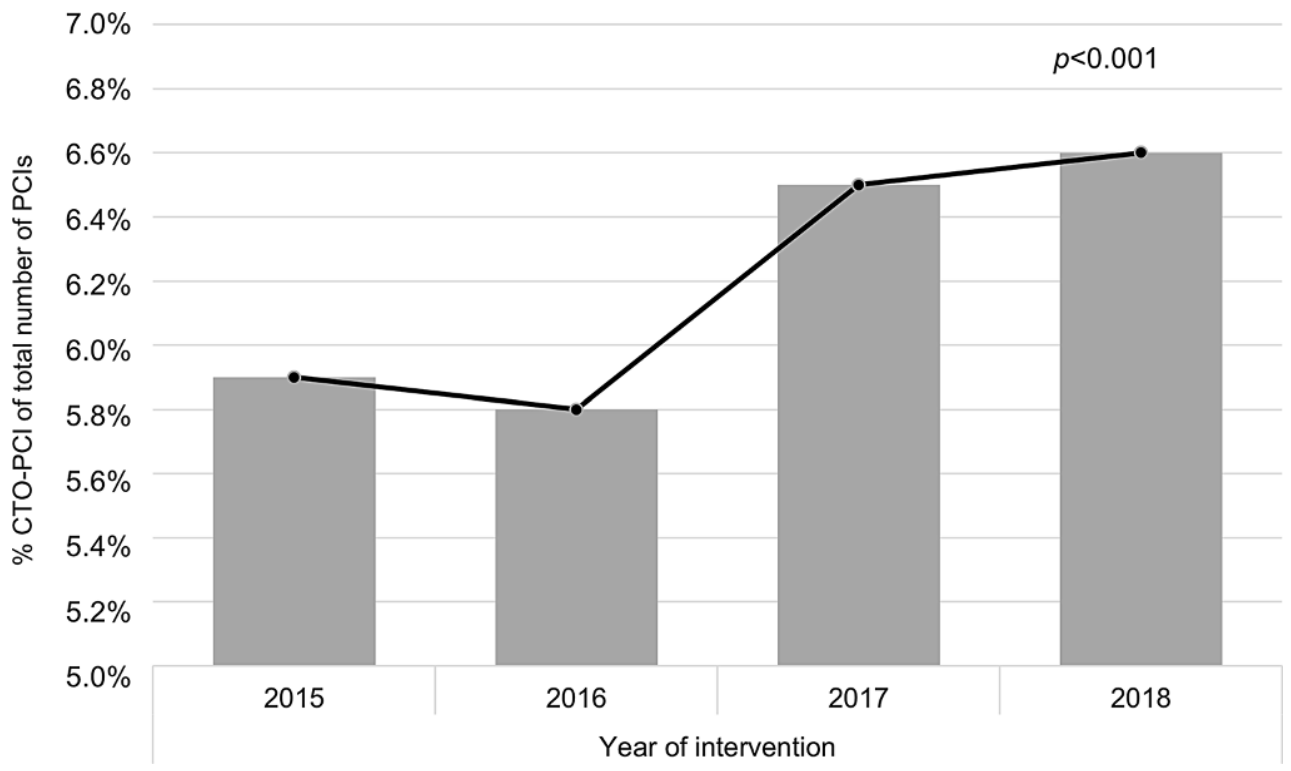


Hier steht eine Anzeige.

Springer 
Hier steht eine Anzeige.

Springer 
Table 1 Baseline characteristics of percutaneous coronary intervention $(P C /)$ patients with or without chronic total occlusion (CTO) registered in the Netherlands Heart Registration

\begin{tabular}{|c|c|c|c|c|c|}
\hline & CTO patients & & Non-CTO patients & & \\
\hline & & Available Data $(n)$ & & Available Data (n) & $p$-Value \\
\hline Age, years & $65.7 \pm 10.7$ & 6,105 & $67.2 \pm 11.1$ & 75,429 & $<0.001$ \\
\hline Male gender & $4,687(76.8)$ & 6,105 & $53,406(70.8)$ & 75,429 & $<0.001$ \\
\hline Diabetes mellitus & $1,533(25.5)$ & 6,022 & $17,321(23.4)$ & 73,978 & $<0.001$ \\
\hline Creatinine level, $\mu$ mol/I (median, IQR) & 86 (IQR 26) & 5,841 & 84 (IQR 27) & 70,867 & $<0.001$ \\
\hline Dialysis & $26(1.0)$ & 2,692 & $215(0.6)$ & 35,173 & 0.027 \\
\hline eGFR, $\mathrm{ml} / \mathrm{min}$ per $1.73 \mathrm{~m}^{2}$ & & 5,848 & & 70,899 & 0.28 \\
\hline$>60$ & 4,459 (76.2) & & $53,630(75.6)$ & & \\
\hline $30-59$ & $1,227(21.0)$ & & $15,343(21.6)$ & & \\
\hline $15-29$ & $105(1.8)$ & & $1,345(1.9)$ & & \\
\hline$<15$ or on dialysis & $26(0.4)$ & & $215(0.3)$ & & \\
\hline LVEF, \% & & 3,697 & & 39,028 & $<0.001$ \\
\hline$>50$ & $2,226(60.2)$ & & $26,070(66.8)$ & & \\
\hline $30-50$ & $1,080(29.2)$ & & 9,968 (25.5) & & \\
\hline$<30$ & $391(10.6)$ & & $2,990(7.7)$ & & \\
\hline Indication for $\mathrm{PCl}$ & & 6,105 & & 75,429 & $<0.001$ \\
\hline Elective & $4,841(79.3)$ & & $39,177(51.9)$ & & \\
\hline NSTEMI & $1,264(20.7)$ & & $36,252(48.1)$ & & \\
\hline Multi-vessel disease & 3,321 (55.2) & 6,012 & $35,639(47.6)$ & 74,828 & $<0.001$ \\
\hline Previous MI & $2,048(34.1)$ & 5,999 & $19,393(26.3)$ & 73,717 & $<0.001$ \\
\hline Previous PCI & $1,126(31.2)$ & 3,612 & $13,911(31.2)$ & 44,637 & $>0.99$ \\
\hline Previous CABG & 877 (14.4) & 6,071 & $8,268(11.1)$ & 74,579 & $<0.001$ \\
\hline Year of intervention & & 6,105 & & 75,429 & 0.25 \\
\hline 2015 & $1,348(22.1)$ & & $15,870(21.0)$ & & \\
\hline 2016 & $1,295(21.2)$ & & $16,095(21.3)$ & & \\
\hline 2017 & $1,718(28.1)$ & & $21,336(28.3)$ & & \\
\hline 2018 & 1,744 (28.6) & & $22,128(29.3)$ & & \\
\hline
\end{tabular}

31 December 2018. In 28,685 procedures the CTO status was not registered. A total of 8,343 of 133,042 procedures $(6.3 \%)$ included a CTO in one of the treated arteries (Fig. 1). The proportion of CTOPCIs in the total number of PCIs increased significantly over time from $5.9 \%$ in 2015 to $6.6 \%$ in 2018 ( $p<0.001$; Fig. 2). After applying the exclusion criteria, 6,105 CTO-PCIs were identified. Baseline characteristics are displayed in Tab. 1. CTO patients were more frequently male $(76.8 \%$ vs $70.8 \%, p<0.001)$, younger (65.7 years vs 67.2 years, $p<0.001$ ), more often had diabetes mellitus $(25.5 \%$ vs $23.4 \%, p<0.001)$, reduced LVEF $<50 \%(39.8 \%$ vs $33.2 \%, p<0.001)$, multivessel disease $(55.2 \%$ vs $47.6 \%, p<0.001)$, previous MI (34.1\% vs $26.3 \%, p<0.001)$ and previous CABG $(14.4 \%$ vs $11.1 \%, p<0.001$ ) than patients without CTO.

Procedural characteristics of CTO-PCIs are displayed in Tab. 2. The majority of procedures were performed via the radial artery $(67.4 \%)$. Very sparse data about the use of double access were available. The most commonly treated artery was the right coronary artery $(42.8 \%)$, and most interventions included stent placement $(83.9 \%)$, which could be considered an equivalent for technical success of CTO-PCI in this registry.

\section{Clinical outcomes}

The median duration between intervention and follow-up was 23 months (IQR 16-36). The 30-day mortality was $0.9 \%(57 / 6,066)$ and 1-year mortality $3.7 \%$ $(207 / 5,555)$. In multivariable logistic regression analysis, the strongest predictor of 1-year mortality was renal insufficiency (OR 5.59, 95\% CI 3.25-9.59, $p<0.001$; Tab. 3). Patients with eGFR in the lowest category (i.e. eGFR $<15 \mathrm{ml} / \mathrm{min}$ per $1.73 \mathrm{~m}^{2}$ or on dialysis) and the second-lowest category (i.e. eGFR $15-29 \mathrm{ml} / \mathrm{min}$ per $1.73 \mathrm{~m}^{2}$ ) had the lowest survival rate (log-rank: $p<0.001$; Fig. 3). Other independent predictors of 1-year mortality were LVEF $<30 \%$ (OR 3.43, 95\% CI $2.00-5.90, p<0.001$ ), the presence of previous MI (OR $1.62,95 \%$ CI 1.14-2.31, $p=0.007$ ) and age (OR 1.06 per year increment, 95\% CI 1.04-1.07, $p<0.001)$. Figure S1 (Electronic Supplementary Material) shows the 
Table 2 Procedural characteristics of interventions for chronic total occlusions

\begin{tabular}{|l|c|c|}
\hline Access route 1 & $\begin{array}{l}\text { Interventions } \\
n(\%)\end{array}$ & Available data $n$ \\
\hline Radial artery & & 2,802 \\
\hline Femoral artery & $1,888(67.4)$ & \\
\hline Brachial artery & $902(32.2)$ & \\
\hline Double access used & $12(0.4)$ & \\
\hline Target artery & $21(15.7)$ & 134 \\
\hline Left main/left anterior descending & $1,111(36.4)$ & 3,050 \\
\hline Right coronary artery & $1,305(42.8)$ & \\
\hline Ramus circumflexus & \\
\hline Arterial/venous bypass graft & $585(19.2)$ & \\
\hline Type of procedure & $49(1.6)$ & \\
\hline Stent placement & & 2,918 \\
\hline Drug-eluting stent & $2,448(83.9)$ & \\
\hline Bare-metal stent & $1,725(70.5)$ & \\
\hline Bioresorbable vascular scaffold & $5(0.2)$ & \\
\hline Unknown stent type & $1(0.0)$ & \\
\hline Balloon dilatation & $717(29.3)$ & \\
\hline Aborted procedure & $253(8.7)$ & \\
\hline aIncluding the anterolateral/intermediate artery & \\
\hline & & \\
\hline
\end{tabular}

survival curves stratified for eGFR category for both CTO and non-CTO patients.

CABG $<24$ h occurred in 15 of 5,980 patients $(0.3 \%)$ and in univariable logistic regression analysis only diabetes mellitus was associated (OR 2.97, 95\% CI 1.04-8.49, $p=0.042$; Electronic Supplementary Material, Table S1). Myocardial infarction <30 days occurred in 19 of 4,214 patients $(0.5 \%)$. In univariable logistic regression analysis, renal insufficiency was associated (OR 4.70, 95\% CI 1.07-20.61, $p=0.040$ ) and female gender tended to be associated with MI <30 days (OR 2.45, 95\% CI 0.98-6.10, $p=0.06$; Electronic Supplementary Material, Table S2). TVR $<1$ year occurred in 489 of 4,336 patients $(11.3 \%)$. No predictors of TVR could be identified (Electronic Supplementary Material, Table S3).

\section{Discussion}

We present the outcomes of CTO-PCI in the Netherlands from 2015 to 2018. The amount of missing data was substantial for several variables. We found that the percentage of CTO-PCI as a proportion of the total number of PCIs has increased over the study period, although the rate is still only $6.3 \%$. Patients with CTO were younger, more often male and more frequently had diabetes, multivessel disease, reduced LVEF, previous $\mathrm{MI}$ and previous $\mathrm{CABG}$, compared to patients without CTO. Patients with renal insufficiency had a 6 -fold higher risk for 1-year mortality and a 5-fold

Table 3 Univariable and multivariable logistic regression model for 1-year mortality in patients undergoing a percutaneous coronary intervention $(\mathrm{PCl})$ for a chronic total occlusion

\begin{tabular}{|c|c|c|c|c|c|c|c|c|}
\hline & \multicolumn{4}{|c|}{ Univariable logistic regression } & \multicolumn{4}{|c|}{ Multivariable logistic regression } \\
\hline & \multirow[b]{2}{*}{$\mathrm{OR}$} & \multicolumn{2}{|c|}{ 95\% Confidence Interval } & \multirow[b]{2}{*}{$p$-Value ${ }^{\mathrm{a}}$} & \multirow[b]{2}{*}{ OR } & \multicolumn{2}{|c|}{ 95\% Confidence Interval } & \multirow[b]{2}{*}{$p$-Value ${ }^{\mathrm{a}}$} \\
\hline & & Lower Limit & Upper Limit & & & Lower Limit & Upper Limit & \\
\hline Age, years & 1.06 & 1.05 & 1.08 & $<0.001$ & 1.06 & 1.04 & 1.07 & $<0.001$ \\
\hline Female gender & 1.67 & 1.18 & 2.36 & 0.004 & 1.36 & 0.93 & 1.98 & 0.11 \\
\hline Diabetes mellitus & 1.89 & 1.35 & 2.65 & $<0.001$ & 1.34 & 0.93 & 1.94 & 0.12 \\
\hline \multicolumn{9}{|l|}{$\angle V E F^{\mathrm{b}, \mathrm{c}}$} \\
\hline $30-50 \%$ & 1.96 & 1.23 & 3.11 & 0.005 & 1.50 & 0.91 & 2.45 & 0.11 \\
\hline$<30 \%$ & 4.06 & 2.46 & 6.70 & $<0.001$ & 3.43 & 2.00 & 5.90 & $<0.001$ \\
\hline Renal insufficiency & 9.64 & 5.99 & 15.51 & $<0.001$ & 5.59 & 3.25 & 9.59 & $<0.001$ \\
\hline Multi-vessel disease & 1.34 & 0.95 & 1.87 & 0.09 & & & & \\
\hline Previous MI & 1.81 & 1.31 & 2.52 & $<0.001$ & 1.62 & 1.14 & 2.31 & 0.007 \\
\hline Previous PCF & 1.27 & 0.79 & 2.04 & 0.32 & & & & \\
\hline Previous CABG & 1.80 & 1.22 & 2.67 & 0.003 & 1.24 & 0.80 & 1.93 & 0.34 \\
\hline Presentation with $A C S^{\mathrm{d}}$ & 1.65 & 1.16 & 2.35 & 0.005 & 1.04 & 1.00 & 1.08 & 0.07 \\
\hline \multicolumn{9}{|l|}{ Year of intervention } \\
\hline 2016 & 0.91 & 0.62 & 1.35 & 0.66 & & & & \\
\hline 2017 & 0.97 & 0.66 & 1.44 & 0.89 & & & & \\
\hline \multicolumn{9}{|c|}{$\begin{array}{l}\text { ACS acute coronary syndrome, CABG coronary artery bypass grafting, } L V E F \text { left ventricular ejection fraction, } M I \text { myocardial infarction, } O R \text { odds ratio } \\
\text { a Significant predictors in the univariable model were entered in the multivariable model. An enter model was used for multivariable logistic regression } \\
\text { b The reference category was LVEF }>50 \% \\
\text { c Since the amount of missing data was substantial (i.e. }>20 \% \text { ) a dummy variable for the missing values was included in the regression model (not sh } \\
\text { the tables) } \\
\text { d Elective procedures versus non-ST-elevation ACS as an indication for PCI }\end{array}$} \\
\hline
\end{tabular}


Fig. 3 Survival curves, stratified by category of estimated glomerular filtration rate $(e G F R)$

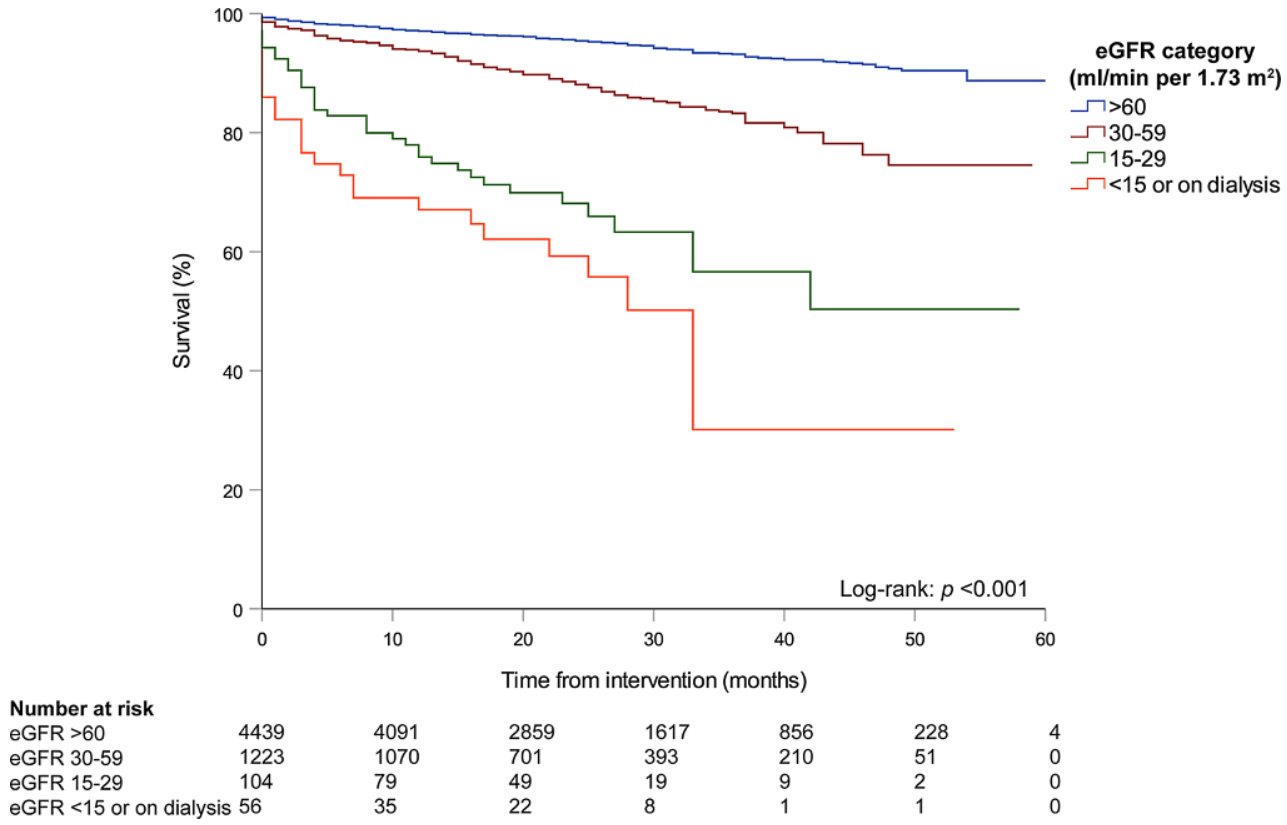

higher risk for 30-day myocardial infarction. Patients with diabetes mellitus had a 3-fold higher risk for urgent $\mathrm{CABG}<24 \mathrm{~h}$ after the procedure.

\section{Clinical outcomes}

Our numbers illustrate that, despite growing success rates and improved techniques, CTO-PCI still remains an infrequently performed procedure. Previously, Hoye et al. reported that from 1992 to 2002 the total number of PCI procedures in a tertiary centre in the Netherlands almost doubled, while the number of CTO-PCIs only slightly increased [9]. The authors reported a CTO-PCI rate of $\sim 10 \%$ of all PCI procedures in 2002 at their tertiary care hospital, while we found a rate of only $6.3 \%$ in the NHR, which includes both tertiary and secondary care hospitals. This is comparable to the $5.8 \%$ reported previously from the nationwide Swedish Coronary Angiography and Angioplasty Registry [7]. Due to its high complexity and success rates of around $80-90 \%$, it is advised that CTO-PCI should be reserved mainly for specialty centres with large volumes and skilled operators $[10,12]$. This results in lower nationwide numbers of CTOPCIs compared to tertiary centres.

The success rates of $80-90 \%$, together with a marked risk for complications, should be weighed against a modest clinical benefit of CTO-PCI over medical therapy alone according to randomised clinical trials [13-16]. These trials demonstrated a significant improvement of symptomatology after CTO-PCI, while mortality rates, the incidence of major adverse cardiac events and left ventricular function did not change when compared to medical therapy alone. We found that renal insufficiency was the strongest predictor of reduced mortality in patients with CTO. It has been demonstrated that chronic kidney disease is a frequent comorbidity among CTO patients, and previous studies reported an incidence of approximately $25 \%$, which is comparable to our data $[17,18]$. We demonstrated that CTO patients with renal insufficiency were at a 6 -fold higher risk for mortality after PCI compared with patients without renal insufficiency. Particularly patients in the two lowest categories (i.e. eGFR $<15 \mathrm{ml} / \mathrm{min}$ per $1.73 \mathrm{~m}^{2}$ and $15-30 \mathrm{ml} / \mathrm{min}$ per $1.73 \mathrm{~m}^{2}$ ) had the worst rate of survival compared to patients with normal or only moderately impaired kidney function. Accordingly, the above-mentioned studies by Moroni et al. and Tajti et al. demonstrated that the presence of chronic kidney disease is associated with an increased risk for both in-hospital and long-term complications after CTO-PCI [17, 18]. In the meta-analysis of Moroni et al. lower procedural and technical success rates of CTO-PCI were also described in this specific patient population [17] while, on the other hand, the exposure of these patients to high contrast doses could lead to an acute or chronic deterioration of their renal function [19]. Hence, in this vulnerable patient population a more restrictive approach with refrainment from PCI could be preferable. It is therefore of great clinical importance to take the presence of renal insufficiency into account when referring patients for CTO-PCI.

\section{Netherlands Heart Registration}

The NHR is a national registry initiated in 2017, in which all cardiovascular interventions performed in the Netherlands are registered. The NHR publishes annual quality reports on the frequencies and outcomes of these interventions for physicians to ensure and improve the quality of cardiovascular care. 
A well-maintained nationwide registry has important clinical value in providing real-world data, in addition to controlled clinical trials that adhere to various exclusion criteria. Unfortunately, in the NHR the amount of missing data was substantial for several baseline characteristics as well as some outcome measures, hampering proper data analysis. However, the completeness and accuracy of data input has improved since the inception of the NHR. It should be emphasised that appropriate and complete data input by all physicians and data managers is of great importance to ensure the clinical and qualitative value of a nationwide registry.

\section{Limitations}

Several limitations should be acknowledged. First, since a CTO was defined in the registry as the presence of a CTO in the treated vessel, it cannot be ascertained that the PCI concerned treatment of the CTO. In the most recent audit, performed in 2019 on a total of 2,500 records at 29 sites, a 1\% discrepancy was found for the CTO variable between the source documentation and the registration. There, the CTO variable was screened as being the target lesion of the PCI procedure. Therefore, we interpreted this variable accordingly. Second, in the NHR there are currently only a limited number of variables that concern information about the CTO intervention. The recording of more relevant CTO variables could lead to more in-depth analysis of this specific patient population. Suggested CTO variables for inclusion in the NHR are displayed in the Electronic Supplementary Material (Table S4). Third, there is no adjudication of endpoints. However, an audit is randomly performed to ensure data quality and uniformity. Lastly, no control group of CTO patients not undergoing PCI was included; therefore, comparisons between treatment strategies could not be made.

\section{Conclusion}

In this nationwide registry, we found that the number of CTO-PCIs is increasing, although the procedure is still infrequently performed. CTO patients were younger, more often male and more frequently had reduced LVEF and concurrent cardiovascular disease compared with patients without CTO. Renal insufficiency was identified as the most important predictor of 1-year mortality and 30-day myocardial infarction, and diabetes mellitus was associated with urgent CABG $<24 \mathrm{~h}$ after the CTO procedure. Identification of patients at risk for poor clinical outcomes could optimise the referral of appropriate patients for CTO revascularisation.

Acknowledgements On behalf of the PCI Registration Committee of the Netherlands Heart Registration, consisting of: G. Amoroso, OLVG; E.K. Arkenbout, Tergooi; S. Aydin, VieCuri
Medisch Centrum; J. Brouwer, Medisch Centrum Leeuwarden; C. Camaro, RadboudUMC; J. Daemen, Erasmus Medisch Centrum; P. Danse, Rijnstate; S.F. de la Fuente, Jeroen Bosch Ziekenhuis; M. van der Ent, Maasstad Ziekenhuis; R. Erdem, ZorgSaam; P. den Heijer, Amphia; J.P.S. Henriques, Amsterdam UMC, locatie AMC; A.W.J. van 't Hof, Zuyderland MC; A.W.J. van 't Hof, Academisch Ziekenhuis Maastricht; I. Karalis, Leids Universitair Medisch Centrum; A. Kraaijeveld, UMC Utrecht; J.P. van Kuijk, Sint Antonius Ziekenhuis; E. Lipsic, Universitair Medisch Centrum Groningen; M. Magro, Elisabeth-TweeSteden Ziekenhuis; K.M.J. Marques, Amsterdam UMC, locatie VUmc; T. Oude Ophuis, Canisius Wilhelmina Ziekenhuis; J. van Ramshorst, Noordwest Ziekenhuisgroep; V. Roolvink, Isala; W.T. Ruifrok, Treant Zorggroep; M. Scholte, Albert Schweitzer Ziekenhuis; C.E. Schotborgh, Haga Ziekenhuis; B.J. Sorgdrager, Haaglanden Medisch Centrum; F. Spano, Meander Medisch Centrum; M.G. Stoel, Medisch Spectrum Twente; K. Teeuwen, Catharina Ziekenhuis

Conflict of interest A. van Veelen, B.E.P.M. Claessen, S. Houterman, L.P.C. Hoebers, J. Elias, J.P.S. Henriques and P. Knaapen declare that they have no competing interests.

Open Access This article is licensed under a Creative Commons Attribution 4.0 International License, which permits use, sharing, adaptation, distribution and reproduction in any medium or format, as long as you give appropriate credit to the original author(s) and the source, provide a link to the Creative Commons licence, and indicate if changes were made. The images or other third party material in this article are included in the article's Creative Commons licence, unless indicated otherwise in a credit line to the material. If material is not included in the article's Creative Commons licence and your intended use is not permitted by statutory regulation or exceeds the permitted use, you will need to obtain permission directly from the copyright holder. To view a copy of this licence, visit http://creativecommons.org/licenses/by/4.0/.

\section{References}

1. Sianos G, Werner GS, Galassi AR, et al. Recanalisation of chronic total coronary occlusions: 2012 consensus document from the EuroCTO club. EuroIntervention. 2012;8:139-45.

2. Hoebers LP, Claessen BE, Dangas GD, et al. Contemporary overview and clinical perspectives of chronic total occlusions. NatRev Cardiol. 2014;11:458-69.

3. Christofferson RD, Lehmann KG, Martin GV, et al. Effect of chronic total coronary occlusion on treatment strategy. Am JCardiol. 2005;95:1088-91.

4. Tsai TT, Stanislawski MA, Shunk KA, et al. Contemporary incidence, management, and long-term outcomes of percutaneous coronary interventions for chronic coronary artery total occlusions: insights from the VACART program. JACC Cardiovasc Interv. 2017;10:866-75.

5. Fefer P, Knudtson ML, Cheema AN, et al. Current perspectives on coronary chronic total occlusions: the Canadian Multicenter Chronic Total Occlusions Registry. J Am Coll Cardiol. 2012;59:991-7.

6. Claessen BE, van der Schaaf RJ, Verouden NJ, et al. Evaluation of the effect of a concurrent chronic total occlusion on long-termmortality andleft ventricularfunctionin patients after primary percutaneous coronary intervention. JACC Cardiovasc Interv. 2009;2:1128-34.

7. Ramunddal T, Hoebers LP, Henriques JP, et al. Chronic total occlusions in Sweden - a report from the Swedish Coronary 
Angiography and Angioplasty Registry (SCAAR). Plos One. 2014;9:e103850.

8. Hoebers LP, Vis MM, Claessen BE, et al. The impact of multivessel disease with and without a co-existing chronic total occlusion on short- and long-term mortality in STelevation myocardial infarction patients with and without cardiogenic shock. Eur J Heart Fail. 2013;15:425-32.

9. Hoye A, van Domburg RT, Sonnenschein K, Serruys PW. Percutaneous coronary intervention for chronic total occlusions: the Thoraxcenter experience 1992-2002. Eur Heart J. 2005;26:2630-6.

10. Konstantinidis NV, Werner GS, Deftereos S, et al. Temporal trends in chronic total occlusion interventions in Europe. Circ Cardiovasc Interv. 2018;11:e6229.

11. NederlandseHartRegistratie(NHR). www.nederlandsehart registratie.nl. Accessed Nov 2020.

12. Brilakis ES, Banerjee S, Karmpaliotis D, et al. Procedural outcomes of chronic total occlusion percutaneous coronary intervention: a report from the NCDR (National Cardiovascular Data Registry). JACC Cardiovasc Interv. 2015;8:245-53.

13. Werner GS, Martin-Yuste V, Hildick-Smith D, et al. A randomized multicentre trial to compare revascularization with optimal medical therapy for the treatment of chronic total coronary occlusions. Eur HeartJ. 2018;39:2484-93.
14. Henriques JP, Hoebers LP, Ramunddal T, et al. Percutaneous intervention for concurrent chronic total occlusions in patients with STEMI: the EXPLORE Trial. J Am Coll Cardiol. 2016;68:1622-32.

15. Lee SW, Lee PH, Ahn JM, et al. Randomized trial evaluating percutaneous coronary intervention for the treatment of chronic total occlusion. Circulation. 2019;139:1674-83.

16. Mashayekhi K, Nuhrenberg TG, Toma A, etal. Arandomized trial to assess regional left ventricular function after stent implantation in chronic total occlusion: the REVASC trial. JACC Cardiovasc Interv. 2018;11:1982-91.

17. Moroni F, Spangaro A, Carlino M, et al. Impact of renal function on the immediate and long-term outcomes of percutaneous recanalization of coronary chronic total occlusions: a systematic review and meta-analysis. Int J Cardiol. 2020;317:200-6.

18. Tajti P, Karatasakis A, Danek BA, et al. In-hospital outcomes of chronic total occlusion percutaneous coronary intervention in patients with chronic kidney disease. J Invasive Cardiol. 2018;30:E113-E21.

19. Azzalini L, Ojeda S, Demir OM, et al. Recanalization of chronic total occlusions in patients with vs without chronic kidney disease: the impact of contrast-induced acute kidneyinjury. Can J Cardiol. 2018;34:1275-82. 